\title{
The Design and Implementation of Public English Online Learning System for Effective Education
}

\author{
GUO Leilei ${ }^{1, a}$, LIU Mengying ${ }^{2}$, XIAO Hong ${ }^{3}$ \\ ${ }^{1,2}$ Sci-tech School of Gannan Normal College, Ganzhou 341000,China \\ ${ }^{3}$ Ganzhou investigation team of National statistics bureaus, Ganzhou 341000,China \\ agrape_1118@163.com
}

Keywords: Online Learning; Computer Platform; Public English Education;

\begin{abstract}
With the rapid development of Education and Internet technology, the combination of the two methods is well appreciated recently. In recent years, a new kind of network course teaching mode MOOC in the field of distance education. MOOC appearance caused a digital tsunami in the field of remote education, have a huge impact on the traditional teaching model, received extensive attention of the remote education industry. We design and implement the novel online based platform for online English education. We analyze the business model and the organization of the proposed system. We believe our proposed platform will largely enhance the current learning module.
\end{abstract}

\section{Introduction}

With the increasing development of Internet technology and the concept of education and the increasing integration of information technology, distance education based on the technology of emerging innovation model appear constantly. In recent years, a new kind of network course teaching mode MOOC (Massive Open Online Course, Massive Open Online courses) in the field of distance education. MOOC appearance caused a digital tsunami in the field of remote education, have a huge impact on the traditional teaching model, received extensive attention of the remote education industry. Learning management system is the main media of the open and distance education, to assist teachers in teaching activities, and provides the powerful support to realize teaching interaction. (Zhang Hanyu etc., 2013) however the most traditional learning management system framework for online course, only supports unilateral access to course knowledge, learners with based on the theories of language associated with more interactive MOOC curriculum support is inadequate, therefore, it is necessary for the current learning management system framework to improve, to adapt to the MOOC curriculum development [1-3]. Based on this, this article on the basis of analyzing the MOOC teaching mode and the LTSA model, this paper proposes a MOOC teaching mode of learning management system framework.

Online course production does not occur in a vacuum. Systems, processes, and workflow is made up of "business function institutions, including the study of market demand, market expectations, course distribution scheme of building flexibility to adapt to the market, technology and volatility. Greenberg strongly points out that university is indeed a enterprises, if they are growing network of higher education market competition, they need to take a hard look at their own culture and behavior [4-5]. Must occur at all levels, the most important thing is that, in the field of teaching, in is no longer 16 weeks of the term, teachers are no longer is the only "experts", the classroom is no longer and any time. For online higher education market competition, is very simple, institutions need to be relevant, high quality products to market quickly. It is no longer feasible production time, 18 to 24 months and leaves the format, navigation, and final course products look and feel of each course at the discretion of the developer. Service rapidly in a student's market expectations, consistency, and quality, more streamlined production method is now needed. High quality of network curriculum development and delivery target mission critical basic CSU-Global campus. Therefore, the investment in quality, teachers and teaching personnel support model described in this article [6-7]. Recent Sloan - C reports indicate that about three-quarters of respondents reported from public 
instruction, online education important long-term strategic agency. Integration of online education institutions strategic planning and goal setting process achieve the desired level of quality is crucial to the perfect competition industry of network education

\section{Platform Design and Implementation}

The Business Model. It is also important to emphasize that curriculum developers customers, also it is has become a competitive market. In a market, there are abundant job opportunities online course developers and faculty, institutions must retain the best staff to become and remain competitive, at the same time provide quality online course materials. Teachers and other subject matter expert (SME) have high expectations, the process of support, expectations, and the workload involved in producing online courses. Online course of the production process must consider allocation plan; In other words, to whom and classes will be distributed in where? Course is developing to deliver a global audience, and probably, in the high capacity. Even temporarily broke into the network in the field of institutions, the establishment of a process that can handle the volume after will save time and effort and support scalability. Production process framework must be flexible enough to adapt to changes in technology, in anticipation of a student and teacher development, a new study in the field of online teaching, and course changes. Anyhow, MOOC way to learn more in line with the characteristics of learning under the network environment, learners can use a form of informal learning, good communication with others; And abundant learning resources, provided by the learners can learn not only the teacher knowledge, still can get knowledge from other learners, the boundary of the learners knowledge in theory to get unlimited expansion. For this reason, we suggest that the concurrent curriculum revision and maintenance of the framework, constantly forced the quantitative and qualitative assessment of the efficiency of the production team framework, and maintain according to need the flexibility to adjust. In short, of course, the production business model is a framework, but should be flexible and dynamic. The general circle of the system is shown in the figure 1 .

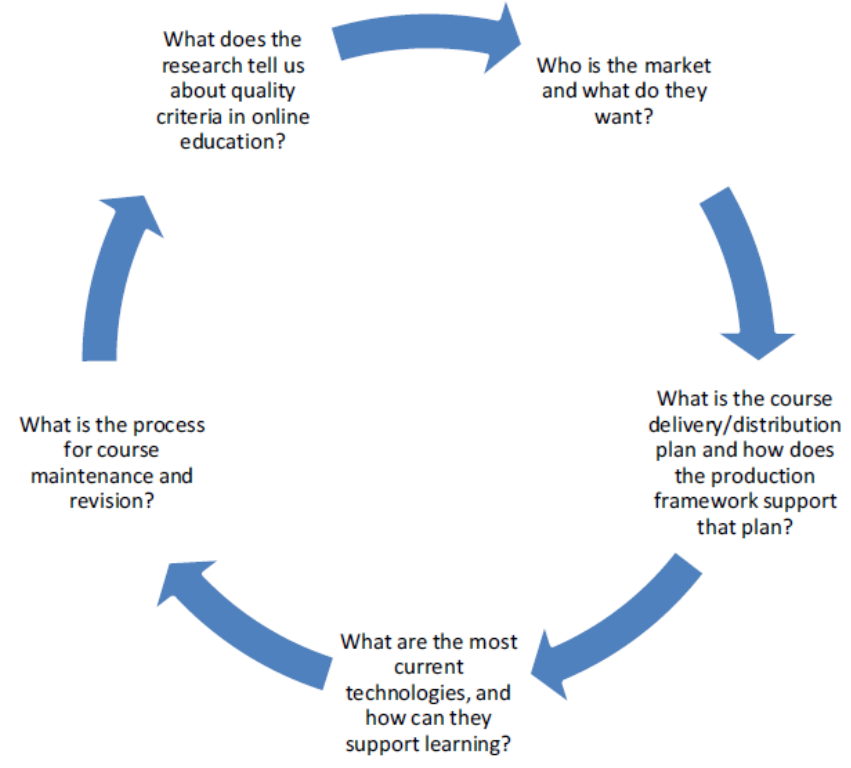

Figure 1. The General Circle of the System

The Basic Pattern of Network Curriculum. Network course is through the network performance of a subject of the sum of teaching content and implementation of teaching activities, including two parts, namely according to certain teaching target, teaching strategy to organize the teaching content and support network teaching environment. Online course as distance education is an important media, both at home and abroad has been a rapid development in recent years. Its basic features are: first, network curriculum is the curriculum, so it is course all elements, such as teaching target, teaching content, teaching design, teaching activities, teaching evaluation, etc. Second, the network course is mainly for the network education services, the network teaching is a kind of open 
teaching mode, overcome the limit of time and space, there are so many ways to learn, learners can learn through a variety of terminals, such as PC, mobile phone, PAD, etc. Network curriculum embodies the characteristics of online teaching in the teaching process is the separation of teaching and learning. The basic characteristics of the network course, but at the same time have their own characteristics, such as the course of many learners, in theory there is no limit to the number of; Learners can refer to their own preferences and habits, the use of all kinds of social software to participate in the learning, etc. MOOC, moreover, is a kind of emergent curriculum, course contains knowledge increased with the progress of the course. In general, the traditional network curriculum and MOOC in the core idea and operation mode have great differences, mainly reflected in the following three aspects. (1) The way to learn. In traditional network curriculum, teachers through the platform release course resources, maintenance of curriculum content. Learners through the platform to access the network course, access to learning resources, and the ways to acquire knowledge is simple linear fashion. That learners can unilaterally derives from the network curriculum knowledge, lack of contribution to the course, more lack of interaction with other learners in a timely manner. Associated learning theory include: the main point of the information is a node, knowledge is the connection, understanding is highlight characteristics of network; Learners through path searching and significance to construct knowledge areas for exploration and consultation, the path to search for clues to involve all kinds of information navigation, meaning construction is a process of creating a connection; Learners through artificial products (Artifacts) to represent their understanding of knowledge. (2) The course content generation. Traditional in the construction of network curriculum, the teacher is in the center of learning and activities, teachers teaching design, responsible for providing teaching resources and curriculum content. MOOC course is a kind of emergent curriculum, course content expansion and extension with the progress of the course, and the knowledge is growing. At the beginning of the course, course content repository only organizers provide some knowledge of prefabricated. In the process of course to carry out, organizer arrange the learning activity and discussion, the theme of the learners to participate in activities, in view of the subject are discussed, thinking and communication. Then the organizers on the content of the learners to generate sorting and filtering to form a new curriculum content, in the form of RSS or email sharing. (3) The course structure. MOOC content characteristics of the unstructured also reflect the MOOC more is to use a form of informal learning. Informal learning is outside of formal learning, mainly based on the various theme activities, carried out between learners learn. Anyhow, MOOC way to learn more in line with the characteristics of learning under the network environment, learners can use a form of informal learning, good communication with others; And abundant learning resources, provided by the learners can learn not only the teacher knowledge, still can get knowledge from other learners, the boundary of the learners knowledge in theory to get unlimited expansion. The structure is shown in the figure 2 .

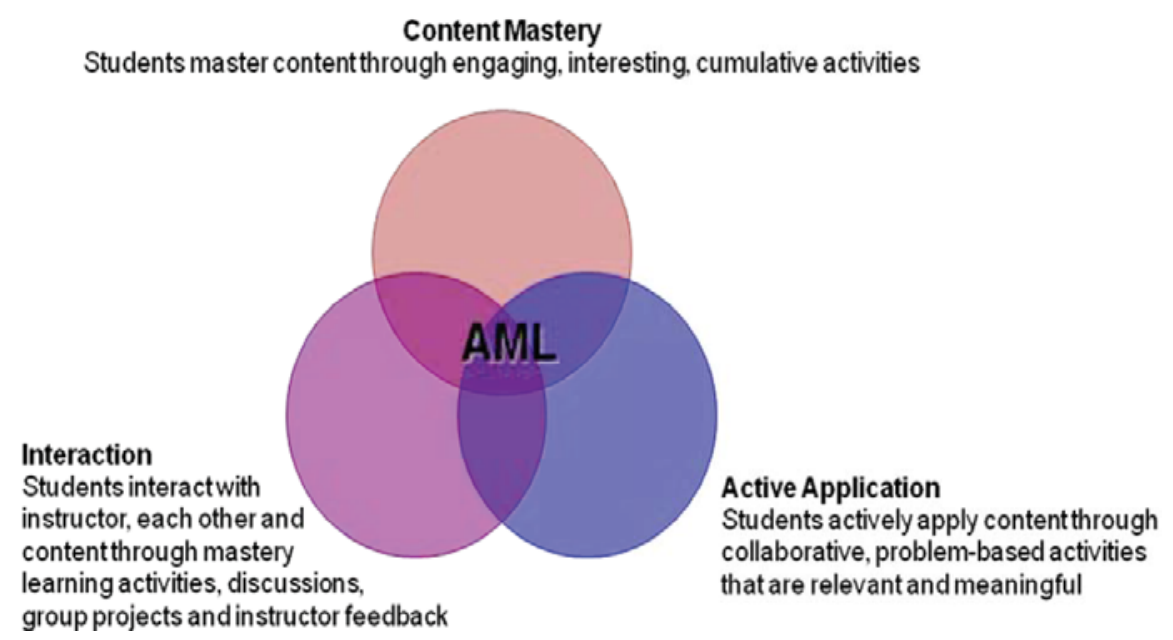

Figure 2. The Structure of the Basic Pattern 
The Advantages of the Proposed System. First, the traditional Wiki and Blog as the main carrier of course center platform, the function is relatively simple, learners scattered in different terminals of the complex network, easy to drown in the huge amounts of information. MOOC and the use of learning management system for management, can provide learners with the integration of learning space, make the learners in the learning space of the unified all kinds of interactive communication, more fully collaborative learning. Second, the use of learning management system to effectively collect and analyze the learners in learning activities and topic discussion of various data, to the learner's learning situation has a detailed record. In addition, the learning management system also can track the learner's learning situation, timely to motivate learners, such as sending an E-mail reminder not logged-in user for a long time. Third, MOOC for learners to have a certain threshold, require learners to have certain knowledge background and technological literacy. Learning management system can carry on the systematic and structured arrangement of curriculum knowledge and induction, for beginners' course guidance and help. Fourth, based on the learning management system to carry out the MOOC to formal learning and informal learning organically fuses in together. In LMS_MOOC, learners can be informal learning through interaction agent components, can also learn by teaching agent components access repository, a formal learning. With minor adjustments and adaptations, this model should help institutions create a process for organizing online course development into an efficient, coherent, and focused practice. As we continue to learn from our peers, research online learning, and keep learning from our mistakes our model should evolve. This model is currently being implemented at CSU-Global Campus, and formalized research to evaluate the model based on faculty satisfaction, efficiency, quality of design, and student learning outcomes is planned for 2008-2009. Preliminarily, the feedback has been positive and we are looking forward to reporting on the efficacy of the model and practical lessons learned in subsequent reports. In summary, our designed system is robust and efficient.

\section{Conclusion and Summary}

With the increasing development of Internet technology and the concept of education and the increasing integration of information technology, distance education based on the technology of emerging innovation model appear constantly. In recent years, a new kind of network course teaching mode MOOC in the field of distance education. MOOC appearance caused a digital tsunami in the field of remote education, have a huge impact on the traditional teaching model, received extensive attention of the remote education industry. Online course production does not occur in a vacuum. Systems, processes, and workflow is made up of "business function institutions, including the study of market demand, market expectations, course distribution scheme of building flexibility to adapt to the market, technology and volatility. Greenberg strongly points out that university is indeed enterprises, if they are growing network of higher education market competition and they need to take a hard look at their own culture and behavior. Through our analysis, we designed a novel robust platform and in the future, we plan to conduct more literature review to polish the current system.

\section{References}

[1] Binti Jamil N J, Tasir Z. Students' Social Presence in Online Learning System[C]. //Teaching and Learning in Computing and Engineering (LaTiCE), 2014 International Conference on. IEEE, 2014:289 - 292.

[2] Jian H. The Concept of Online Learning System for University Librarian Based on Internet[J]. Library Work and Study, 2014.

[3] Business J O E F, p- V N. Assessment of the Effectiveness of an Online Learning System in Improving Student Test Performance[J]. Journal of Education for Business, 2014, 89(5):248-256. 
[4] Dias S B, Diniz J A. Towards an enhanced learning management system for blended learning in higher education incorporating distinct learners' profiles.[J]. Journal of Educational Technology \& Society, 2014.

[5] Jo J, Park K, Lee D, et al. An Integrated Teaching and Learning Assistance System Meeting Requirements for Smart Education[J]. Wireless Personal Communications, 2014.

[6] Wei-guang L, Xiao-dan G. A System Development of Moodle-Based Online Learning Platform for Library Readers- A Case Study of the Construction of Information Education Network Platform in Tibet University for Nationalities[J]. Journal of Library and Information Sciences in Agriculture, 2014.

[7] Shenglei L. The Research of Curriculum Resource Construction of Provincial Cadres Online Learning Platform[J]. Journal of Shanxi Radio \& TV University, 2014. 